ISSN : 2356-4164

\title{
PERLINDUNGAN HAK ASASI MANUSIA SECARA INDIVIDUAL OLEH DEWAN HAK ASASI MANUSIA PBB SUATU TINJAUAN TERHADAP TAHANAN RUMAH AUNG SAN SUU KYI
}

\author{
I Gusti Ayu Apsari Hadi \\ Jurusan Ilmu Hukum Universitas Pendidikan Ganesha \\ E-mail: apsari.hadi@gmail.com
}

\begin{abstract}
ABSTRAK
Munculnya era baru Dewan HAM sebagai pengganti dari Komisi HAM PBB memiliki fungsi pokok ialah sebagai pengawas yang membongkar kasus-kasus pelanggaran HAM di muka bumi. Salah satu peran Dewan HAM PBB yang dibentuk sejak tahun 2006 ialah menjamin HAM secara individu terhadap tahanan rumah Aung San Suu Kyi, seorang tokoh prodemokrasi di Myanmar.Penahanan dan pelanggaran HAM yang terjadi pada Suu Kyi telah melanggar pasal 9, 10, dan 19 UDHR, yakni bahwa seseorang berhak atas kebebasan untuk mengemukakan pendapat, larangan atas penangkapan sewenang-wenang hingga memiliki hak atas pengadilan yang adil dalam pasal 10. Sedangkan dalam ICCPR juga terdapat ketentuan mengenai pelanggaran yang dilakukan Myanmar terhadap Aung San Suu Kyi pada pasal 9 angka (1) tentang penahanan sewenang-wenang.Melalui mekanisme Universal Periodic Review Dewan HAM, UPR 10th di Geneva, 24 Januari - 4 Februari 2011 par. 29 menyatakan agar pemerintah Myanmar segera membebaskan Aung San Suu Kyi dari tahanan rumahnya.Hal tersebut mengisyaratkan bahwa negara-negara tidak lagi dapat berlindung di balik kedaulatan teritorialnya atas pelanggaran hak asasi manusia yang terjadi di wilayah negaranya, termasuk Myanmar.
\end{abstract}

Kata Kunci : Hak Asasi Manusia, Individu, Dewan HAM PBB, Aung San Suu Kyi. 
ISSN : 2356-4164

\section{ABSTRACT}

The advent of a new era in lieu of the Human Rights Council of the UN Human Rights Commission has the principal function as a watchdog, as in uncovering cases of human rights violations on earth. One of many role of the UN Human Rights Council is to ensure individual rights against the house arrest of Aung San Suu Kyi, a pro-democracy leader in Myanmar. Detention and human rights violations that occurred on Suu Kyi had violated Articles 9, 10, and 19 UDHR, generally; that a person is entitled to freedom of expression, the prohibition on arbitrary arrest to have the right to a fair trial under article 10. Whereas in the ICCPR there are also provisions regarding violations committed against Aung San Suu Kyi by Myanmar in article 9 point (1) of arbitrary detention. Through the mechanism of the Universal Periodic Review by the Human Right Council, UPR 10 th in Geneva date 24 January-4 February 2011 in paragraph 29 stated that; the government of Myanmar to immediately release Aung San Suu Kyi from house arrest. This suggests that countries can no longer hide behind its territorial sovereignty over human rights violations that occurred in the country, including Myanmar.

Keywords :Human Rights, Individual, Human Rights Council, Aung San Suu Kyi.

\section{PENDAHULUAN}

Sejak berakhirnya Perang Dunia I yakni pada akhir dekade kedua Abad ke 20, Hukum Hak Asasi Manusia (HAM) Internasional sudah mulai menampakkan eksistensinya.Hukum HAM Internasional bermula dari sejarah perkembangan doktrin-doktrin dan institusi-institusi internasional

(http://elsam.or.id/pdf/kursusham/Poko k_pokok_HAM).Namun baru sejak tahun 1945 kebanyakan dari semua yang Jurnal Komunikasi Hukum dianggap sebagai Hukum HAM Internasional muncul yakni sebagai implikasi dari bencana yang ditimbulkan oleh pengingkaran lain dari kaum Nazi terhadap hak asasi manusia (http://elsam.or.id/pdf/kursusham/Tinja uan_Umum_Hukum_HAM.pdf).Dengan adanya peristiwa tersebut maka negaranegara di dunia memutuskan bahwa peningkatan hak asasi manusia dan kebebasan dasar haruslah merupakan satu diantara tujuan utama dari 
ISSN : 2356-4164

pembentukan organisasi Perserikatan Bangsa-Bangsa yang baru.Kendatipun adanya jaminan HAM telah dikembangkan secara progresif oleh banyak pihak, mulai dari negara hingga aktor-aktor non negara, namun dalam kenyataannya masih banyak pihak terjadi pelanggaran HAM di berbagai belahan dunia.

Jika melihat kembali, kasus pelanggaran Hak Asasi Manusia tidak hanya terjadi ketika perang terjadi namun bahkan tidak mungkin menimpa seorang individu di suatu negara berdaulat. Kasus paling menjadi sorotan publik internasional ketika salah satu tokoh prodemokrasi Myanmar, Aung San Suu Kyi menjadi tahanan rumah selama hampir 20 tahun tanpa adanya penuntutan dan pengadilan yang jelas (http://library.uinsby.ac.id).Dalam

berbagai kesempatan, PBB telah berusaha untuk memberikan peringatan keras kepada pemerintah Junta Militer Myanmar agar menghentikan tindakantindakan represif mereka yang tidak mengindahkan hak asasi manusia (http://dunia.vivanews.com).

Mukadimah Piagam PBB pada paragraf 2 menyebutkan, "to reaffirm I fundamental human rights, in the dignity and worth of the human person, in the equal rights of men and women and of nations large and small" (Charter of The United Nations1945).Jadi adanya tekad untuk memperteguh kepercayaan pada hak-hak asasi manusia, harkat dan derajat manusia, serta persamaan hak bagi pria maupun wanita dan bagi segala bangsa besar maupun kecilmenjadi pertimbangan utama PBB dalam rangka ikut serta untuk menyelesaikan kasus pelanggaran HAM yang dialami oleh Suu Kyi (Sri Setianingsih, 2004).

Munculnya era baru Dewan HAM sebagai pengganti dari Komisi HAM PBB memiliki fungsi pokok ialah sebagai pengawas yang membongkar kasus-kasus pelanggaran HAM di muka bumi, di samping membantu negara anggota menyusun instrument-intrumen tentang HAM.Dewan memperkenalkan lembaga baru bernama Universal Periodical Review (UPR) yang dapat meninjau situasi HAM di seluruh negara besar atau kecil. Kiprah Dewan HAM ke depan sangat dipengaruhi oleh kultur banyak negara, terutama negara besar hingga dapat dikatakan tugas Dewan HAM PBB sangat berat. 
ISSN : 2356-4164

Di tahun 2011, salah satu peran Dewan HAM dengan kasus yang dialami Suu Kyi dapat dilihat pada resolusi yang diadopsi oleh Dewan HAM PBB A/HRC/RES/16/24 mengenai situasi HAM di Myanmar. Pada paragraph 3 resolusi tersebut dinyatakan:

Welcomes the release of Daw Aung San Suu Kyi following the most recent period of her arbitrary house arrest, and noting that her release is unconditional, calls on the Government of Myanmar to guarantee the full enjoyment of all human rights, including civil and political rights, and fundamental freedoms, for all people in Myanmar, including Daw Aung San Suu Kyi, in particular with regard to unrestricted movement in and outside the country and unrestricted contact with all domestic stakeholders

Merujuk pada isi resolusi tersebut, dapat dilihat secara jelas betapa perlindungan HAM individu memang menjadi perhatian khusus bagi Dewan HAM PBB.Resolusi tersebut secara tegas mendesak Pemerintah Myanmar untuk menjamin hak-hak sipil dan politik yang dimiliki oleh Suu Kyi.

Dengan melihat pada uraian tersebut, penulis berasumsi bahwa dirasa perlu untuk melakukan kajian lebih lanjut terhadap perlindungan HAM khususnya bagi individu yang dilakukan oleh Dewan HAM PBB.Tindakan penahanan tanpa alasan yuridis yang jelas tentu tidak sejalan dengan apa yang digariskan di dalam International Convenant on Civil and Political Rights (ICCPR) article 9 part (1) menyatakan "Everyone has the right to liberty and security of person. No one shall be subjected to arbitrary arrest or detention. No one shall be deprived of his liberty except on such grounds and in accordance with such procedure as are established by law. Dalam konteks ini, bagaimana sesungguhnya peran Dewan HAM PBB dalam memberikan perlindungan secara individual mengingat terdapat prinsip nonintervensi sebagai prinsip fundamental dalam hukum internasional.

\section{METODE PENELITIAN}

Pengumpulan data/bahan dalam penulisan karya ilmiah ini adalah dengan menggunakan metode penelitian normatif Universitas Pendidikan Ganesha| 38 
ISSN : 2356-4164

Secara garis besar penelitian kepustakaan yang dilakukan berkaitan dengan asas asas hukum yakni asas hukum internasional berkaitan dengan prinsip non-intervensi yang ada dalam Piagam PBB.PBB berhak mengambil tindakan apabila terjadi pelanggaran HAM di suatu negara seperti yang terjadi di Myanmar dalam kasus Aung San Suu Kyi.

PEMBAHASAN

Kedudukan dan Kewenangan Dewan Hak Asasi Manusia PBB

Dewan HAM merupakan salah satu badan PBB yang baru dibentuk untuk menggantikan Komisi HAM PBB. Komisi HAM dibentuk pertama kali oleh ECOSOC pada tahun 1946 dan bersidang setiap tahun (enam mingguan yang diselenggarakan setiap musim semi di Jenewa) (C. de. Rover, 2000).

Tahun 2005 disepakati penggantian Komisi HAM PBB dengan Dewan HAM PBB yang tercantum dalam dokumen akhir KTT PBB. Dalam KTT tersebut juga disepkati beberapa isu utama terkait pembentukan Dewan HAM ialah sebagai berikut :

1. Membentuk sebuah badan baru untuk membantu negara-negara bangkit dari konflik. Timbul ketidakcocokan dalam masalah kontrolnya, dilakukan oleh DK PBB atau oleh MU PBB.

2. Menyerukan negara-negara untuk memikirkan intervensi dalam kasus genosida/pembantaian etnis. Tujuannya untuk mencegah negara-negara melakukan kejahatan genosida.

3. Mengutuk terorisme dalam segala bentuknya.

Majelis Umum PBB yang terdiri dari 170 negara anggota setuju mendirikan Dewan HAM pada tanggal 15 Maret 2006, tetapi empat anggota lainnya yakni Amerika Serikat, Israel, Kepulauan Marshall dan Palau menolak. Sedangkan tiga negara lainnya yaitu Bela Rusia, Iran, dan Venezuela abstain (Masyhur Effendi \& Taufani Sukmana, 2010).Pada pemilihan anggota putaran pertama, Indonesia bersama-sama dengan India, Filipina, Qatar, Bolivia, Nikaragua, Mesir, Angola, Afrika Selatan, Madagaskar, Belanda, dan Slovenia ditetapkan sebagai 
anggota Dewan HAM untuk periode 2007 - 2010. Sedangkan putaran kedua terpilih anggota Korea Selatan, Saudi Arabia, Srilangka, Pakistan, Malaysia, Yordania, Jepang, Banglades, Cina, dan Bahrain.

Fungsi pokok Dewan HAM PBB ialah sebagai pengawas yang membongkar kasus-kasus pelanggaran HAM di muka bumi, di samping membantu negara anggota menyusun undang-undang tentang HAM. Melalui Resolusi MU PBB yang berbunyi, "Decide to establish the Human Rights Council, based in Geneva, in replacement of the Commission on Human Rights, as a subsidiary organ of the General Assembly; the Assembly shall review the status of the Council within five years" (General Assembly Resolution, A/RES/60/251, 2006).Menurut ketentuan tersebut walaupun tidak seperti Komisi HAM yang secara langsung berada di bawah Dewan Ekonomi Sosial, namun sebagai badan subsiderdari Majelis Umum Dewan HAM PBB memiliki kewenangan yang lebih luas dari Komisi HAM PBB.

Dengan tugas utama melakukan tindak lanjut terhadap pelanggaran HAM yang terjadi di dunia Dewan HAM memiliki mandat untuk membentuk subinstitusi - subinstitusi baru dan menetapkan cara kerja yang lebih efektif. Sebuah kelompok kerja untuk pemerintah telah dibentuk yang transparan bagi semua dalam hal perumusan rekomendasi - rekomendasi kongkrit dalam proses peninjauan kembali (Knut D. Asplund, dkk, 2008).

Untuk lebih jelas mengenai kedudukan dan kewenangan Dewan HAM akan diuraikan dalam bentuk struktur organisasi sebagai berikut :

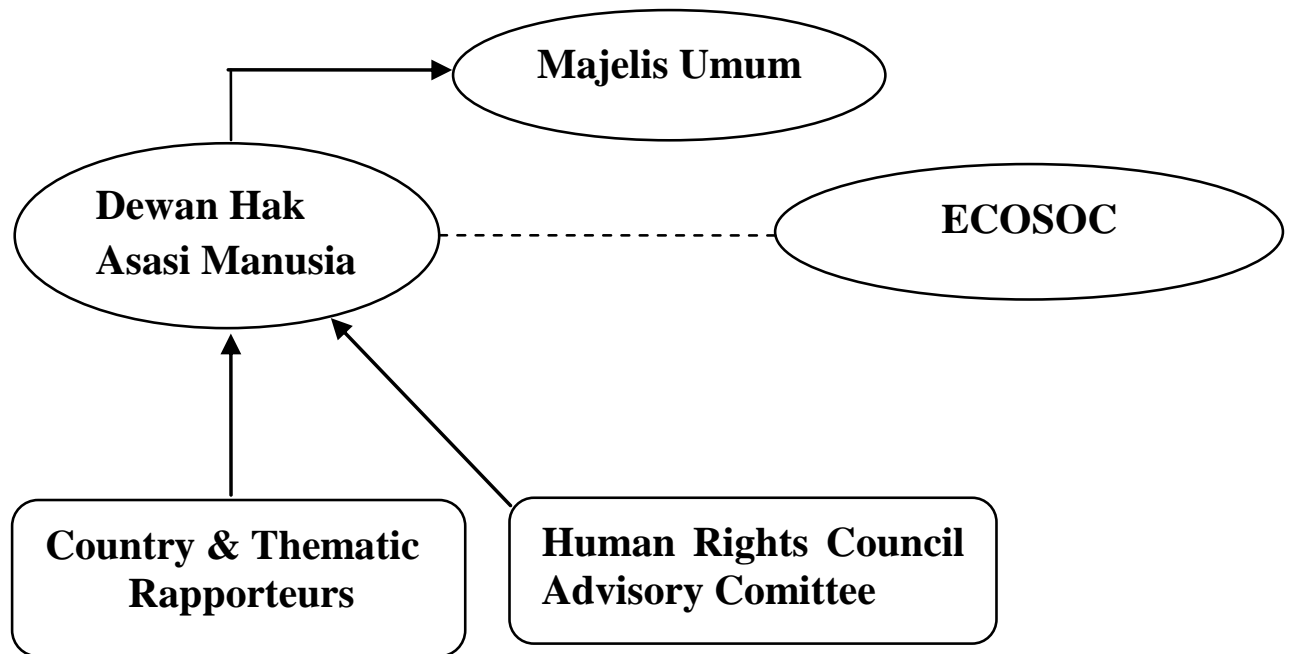

Jurnal Komunikasi Hukum 
Meskipun pembentukan Dewan HAM dilakukan sesuai resolusi Majelis Umum namun kedudukannya tetap tidak dapat disejajarkan dengan Dewan ECOSOC. Mekanisme pemantauan kerja Dewan HAM akan dibantu oleh subdivisisubdivisi di bawa Dewan baik melalui laporan negara-negara (Country \& Thematic Rapporteurs) dan Komisioner Tinggi Hak Asasi Manusia (Human Rights Council Advisory Committee). Adapun sistem pemantauan HAM sendiri terbagi menjadi dua mekanisme yaitu :

1. Berdasarkan piagam (the charter based mechanism)

Berdasarkan piagam adalah badan- badan yang dibentuk melalui piagam PBB.Mekanisme ini yang bersifat khas adalah Dewan Ekonomi dan Sosial, Dewan Hak Asasi Manusia, Majelis Umum, dan Dewan Keamanan. Selain itu terdapat banyak sub-komite dan sub-mekanisme di bawah badan badan utama ini, seperti Komisioner Tinggi Hak Asasi Manusia, Kelompok Kerja, dan lain Jurnal Komunikasi Hukum
- lain. Metode menurut badan badan ini lebih bersifat politik dan kurang bersifat hukum daripada mekanisme perjanjian - perjanjian hak asasi manusia.

2. Berdasarkan perjanjian (the treaty based mechanism)

Berdasarkan perjanjian adalah mekanisme yang dibentuk melalui perjanjian - perjanjian hak asasi manusia yang berada di bawah sistem PBB, terutama komite komite dengan kewenangan untuk memeriksa dan mengevaluasi praktik - praktik hak asasi manusia negara - negara anggota menurut tugas yang berasal dari konvensi - konvensi. Metode kerja mereka terkait erat dengan dokumen - $\quad$ dokumen pembentukannya yang membuat badan - badan ini bersifat legalistik sejak awalnya.

Perlindungan Hak Asasi Manusia Dewan HAM PBB Terhadap Aung San Suu Kyi Universitas Pendidikan Ganesha| 41 
Hak asasi manusia sebagai hak universal yang dimiliki individu sejak lahir dan tidak berhak direnggut oleh orang lain. Sesuai dengan isi pasal 2 UDHR yang menyebutkan bahwa :

Everyone is entitled to all the rights and freedoms set forth in this Declaration, without distinction of any kind, such as race, colour, sex, language, religion, political or other opinion, national or social origin, property, birth or other status. Furthermore, no distinction shall be made on the basis of the political, jurisdictional or international status of the country or territory to which a person belongs, whether it be independent, trust, non-selfgoverning or under any other limitation of sovereignty.

HAM yang melekat pada diri setiap manusia merupakan hak-hak yang membuat mereka diakui kemanusiannya tanpa membedakan jenis kelamin, ras, warna kulit, bahasa, agama, politik, bangsa, status sosial, kekayaan, dan kelahirannya.Termasuk juga dalam hal ini hak untuk hidup layak, merdeka, dan selamat. Sehingga menjadi tugas negara untuk melindungi hak asasi warga negaranya dari pihak-pihak yang ingin meniadakannya serta bertindak sebagai hakim yang adil untuk melindungi dari tindakan pemaksaan, penipuan, dan lain sebagainya yang dapat mengganggu kebebasan dari warga negaranya (Ambarwati, dkk, 2009).

Instrumen hak asasi manusia terkait penegakan hukum HAM dapat ditemukan mulai dari dibentuknya Deklarasi Universal Hak-Hak Asasi Manusia (UDHR) tahun 1948.Bahkan ketika pembentukan Piagam Perserikatan Bangsa-Bangsa pernyataan tentang HAM sudah tercermin dalam penggalan kalimat yang berbunyi "bahwa kemenangan adalah penting untuk menjaga kehidupan, kebebasan, independence, dan kebebasan beragama serta untuk mempertahankan Hak Asasi Manusia dan keadilan.

Setelah UDHR diterima maka semenjak itu PBB terus menerus berusaha keras memprakarsai suatu usaha untuk membentuk perjanjian yang mempunyai kekuatan mengikat. Bila UDHR hanya bersifat himbauan, instrumen-instrumen internasional hak asasi yang timbul dan bersifat mengikat secara tidak langsung akan dapat 
mengawasi pelaksanaan yang efektif hakhak asasi tersebut.

Sejalan dengan hal tersebut maka tanggal 16 Desember 1966, Majelis Umum menerima dua perjanjian tentang hak-hak asasi manusia yaitu International Covenant on Economic, Social and Cultural Rights dan International Covenant on Civil and Political Rights(Boer Mauna, 2005). Kedua perjanjian tersebut menyebutkan adanya hak rakyat untuk menentukan nasib sendiri termasuk hak untuk mengatur kekayaan dan sumber-sumber nasional secara bebas seperti tercantum dalam masing-masing perjanjian (ICCPR, 1966).Sejak munculnya perjanjian ICCPR dan ICESCR tahun 1966 kedudukan individu tidak hanya sebagai objek tetapi juga dalam hal-hal tertentu sebagai subjek hukum internasional.Peningkatan status individu semakin bertambah setelah banyaknya terjadi pembunuhan missal, genosida, kejahatan kemanusiaan, kejahatan perang, dan pelanggaran HAM berat lainnya di belahan dunia setelah Perang Dunia II.

Dalam perspektif hukum internasional kasus pelanggaran HAM yang terjadi pada seorang aktivis pro demokrasi Myanmar, Aung San Suu Kyi penangkapan dan penahanan sewenangwenang yang dilakukan Junta Militer telah melanggar ketentuan yang termuat dalam pasal 9.1 ICCPR "Everyone has the right to liberty and security of person. No one shall be subjected to arbitrary arrest or detention. No one shall be deprived of his liberty except on such grounds and in accordance with such procedure as are established by law".Aturan ini ditujukan kepada badan pengundang-undangan nasional dan kepala badan penegak hukum. Dalam artian tindakan sewenangwenang seperti alasan - alasan penangkapan serta prosedur penahanan harus ditemukan di dalam hukum negara tersebut.

Tidak adanya asas legalitas dalam penahanan Suu Kyi selama hampir 20 tahun terakhir yang dilakukan oleh Junta Militer telah jelas menyiratkan pelanggaran HAM yang dilakukan Myanmar terhadap warga negaranya sendiri. Dalam teori hubungan antara hukum internasional dan hukum nasional "suatu negara tidak dapat mengemukakan ketentuan di dalam konstitusi atau hukum nasionalnya sebagai (alasan) pemaaf atas kegagalan - kegagalannya melaksanakan kewajibannya berdasarkan hukum 
ISSN : 2356-4164

internasional".Adanya fakta bahwa hukum internasional mengikat terhadap semua negara sehingga negara dianggap bertanggung jawab jika terjadi pelanggaran terhadap hukum internasional. Begitu pula terhadap Myanmar yang telah melakukan pelanggaran HAM dengan menangkap dan menahan Suu Kyi yang dianggap menentang pemerintahan Junta Militer kala itu.

Penahanan dan pelanggaran HAM yang terjadi pada Suu Kyi telah melanggar pasal 9, 10, dan 19 UDHR (Human Rights Council, $A / H R C / 10 / 19,2009)$. Ketiga pasal tersebut sama - sama menyebutkan bahwa seseorang berhak atas kebebasan untuk mengemukakan pendapat, larangan atas penangkapan sewenangwenang hingga memiliki hak atas pengadilan yang adil dalam pasal 10 . Sedangkan dalam ICCPR juga terdapat ketentuan mengenai pelanggaran yang dilakukan Myanmar terhadap Aung San Suu Kyi pada pasal 9 angka (1) tentang penahanan sewenang-wenang.

Dewan HAM sebagai organ khusus PBB dalam pelaksanaan kewenangannya memiliki badan-badan subsider yang tugasnya melaporkan secara langsung Jurnal Komunikasi Hukum situasi pelanggaran HAM yang terjadi di negara-negara, khususnya pelanggaran HAM yang dialami Aung San Suu Kyi :

1. Universal Periodic Review (UPR) UPR adalah mekanisme baru Dewan HAM PBB diyakini mampu menjembatani sekaligus mengenali taraf perkembangan pemenuhan HAM di setiap negara. Selain itu UPR adalah mekanisme antarpemerintah yang memungkinkan setiap negara melakukan dialog secara setara. Sehingga dalam hal ini negaranegara yang menyampaikan laporan (country under review) bukanlah "pesakitan" bagi negara-negara lain melainkan untuk membangun kesetaraan, integritas, dan kredibilitas Dewan HAM (Majda El Muhtadj, 2008).

UPR berupa laporan secara periodik setiap empat tahun sekali tentang pemenuhan kewajiban HAM semua negara anggota PBB serta jaminan perlakuan yang sama diantara anggotanya. Menurut Sekretaris Jenderal PBB Ban Ki-moon menyatakan bahwa, "The Universal Periodic Review has great potential to promote and protect human rights in the darkest corners of the world"(http://ohchr.org/EN/HRBodies/U PR).Dalam pernyataan oleh SekJend PBB Universitas Pendidikan Ganesha| 44 
ISSN : 2356-4164

tersebut menyiratkan bahwa UPR merupakan suatu proses yang berpotensi besar untuk memajukan dan melindungi hak asasi manusia dari sisi-sisi buruk di dunia.

UPR melakukan review terhadap satu negara setiap empat tahun sekali, yang mana negara pertama yang direview dipilih berdasarkan kelompok regional dengan memperhatikan distribusi secara geografis. Kemudian pemilihan dilakukan berdasarkan Alphabetical order kecuali ada negara yang bersedia secara sukarela mengajukan diri sebagai negara yang menyampaikan laporan. Review dilakukan oleh kelompok kerja yang terdiri dari negara anggota Dewan yang bertemu 3 kali setiap tahun selama 2 minggu dan akan difasilitasi oleh kelompok tiga negara anggota Dewan yang akan berperan "Rapporteurs".

UPR sebagai mandat dari Dewan HAM sesuai dengan resolusi 60/251 angka 5 huruf (e) merupakan suatu keniscayaan yang mungkin disampaikan di hadapan sidang Dewan HAM PBB. Selain itu UPR juga memungkinkan menerima rekomendasi dari Special Procedures dan Human Rights treaty bodies, serta informasi dari berbagai sumber seperti NGOs dan KOMNAS HAM suatu negara yang akan diperhitungkan sebagai sumber tambahan. Sehingga diharapkan hasil akhir yang didapatkan akan dilaksanakan oleh negara yang bersangkutan.

Melalui mekanisme UPR pula, Dewan HAM menyerukan pembebasan atas tokoh demokrasi Myanmar Aung San Suu Kyi di Geneva. Dalam UPR 10 ${ }^{\text {th }} 24$ Januari - 4 Februari 2011 par. 29 disebutkan "The Secretary-General, the High Commissioner for Human Rights, the Security Council, the General Assembly, the Human Rights Council and the Special Rapporteur on the situation of human rights in Myanmar called for the immediate release of Daw Aung San Suu Kyi, and of all remaining political prisoners." Artinya organ-organ tersebut telah mengeluarkan seruan-seruan agar pemerintah Myanmar segera membebaskan tanpa syarat dan penundaan terhadap Aung San Suu Kyi dari tahanan rumahnya berikut pula tahanan-tahanan politik lain. Namun pemerintah Myanmar tetap berkelit dan tidak menunjukkan keinginan untuk membebaskan para tahanan termasuk Suu Kyi. 
ISSN : 2356-4164

2. Advisory Committee

Badan ini dibentuk berdasarkan resolusi Dewan HAM PBB 5/1 angka 65 yang berbunyi, "The Human Rights Council Advisory Committee (hereinafter "the Advisory Committee"), composed of 18 experts serving in their personal capacity, will function as a think-tank for the Council and work at its direction." Berdasarkan resolusi tersebut menerangkan bahwa fungsi Advisory Committee yang terdiri dari 18 ahlimemiliki fungsi sebagai wadah berpikir bagi Dewan HAM dan juga bekerja secara langsung sesuai arahannya.

Dalam rangka menjalankan tugasnya Komite tidak akan mengadopsi resolusi atau keputusan namun dapat mengusulkan kepada Dewan dalam lingkup tugasnya sebagaimana ditetapkan oleh Dewan HAM. Dalam mandatnya pun komite dituntut untuk mealukan interaksi kepada negara, LSM hak asasi manusia, NGOs, dan entitas masyarakat sipil lainnya

(http://ohchr.org/EN/HRNodies/HRC/A dvisoryCommittee).

Komite melaksanakan dua sesi selama maksimal sepuluh hari kerja setiap tahun.Sesi perdananya telah diadakan pada 4-15 Agustus 2008 di Kantor PBB, Jenewa dan sesi tambahan dimungkinkan selama disetujui oleh Dewan.

\section{Complaint Procedure}

Menurut Resolusi 5/1 angka 85 menyebutkan, "A complaint procedure is being established to address consistent patterns of gross and reliably attested violations of all human rights and all fundamental freedoms occurring in any part of the world and under any circumstances." Jadi Prosedur ini dibentuk untuk melihat ciri-ciri umum serta seberapa sering terjadinya pelanggaran HAM dan hak-hak fundamental lainnya yang terjadi di seluruh belahan dunia tanpa pengecualian.

Prosedur Pengaduan baru didirikan sesuai dengan mandat yang dipercayakan kepada Dewan Hak Asasi Manusia oleh resolusi Majelis Umum yang menyebutkan Dewan diminta untuk meninjau dan jika diperlukan memperbaiki dan merasionalisasi dengan jangka waktu satu tahun setelah penyelenggaraan sidang pertamanya untuk mengurus semua mandat, 
mekanisme, fungsi dan tanggung jawab Komisi Hak Asasi Manusia terdahulu termasuk prosedur 1503 dalam rangka untuk mempertahankan sistem prosedur khusus, saran para ahli dan prosedur pengaduan.

Sesuai dengan resolusi pembentukannya complaint procedure bekerja dengan mekanisme yang memungkinkan individu dan organisasi untuk melaporkan adanya pelanggaran berat HAM yang membutuhkan perhatian Dewan HAM.Prosedur ini mengacu kepada victims-oriented dan bekerja dengan waktu yang lebih fleksibel. Dalam artian bahwa pengaduan ini bersifat rahasia dengan tujuan meningkatkan kerjasama dengan negara yang bersangkutan yakni negara tersebut akan diberitahu ketika diadakan review.

Melalui prosedur ini juga dibentuk dua kelompok kerja, yakni Kelompok Kerja bidang Komunikasi (The Working Group on Communications) dan Kelompok Kerja bidang Situasi (The Working Group on Situations).Dua tersebut dibentuk untuk memeriksa laporan yang dikirmkan dan meminta perhatian Dewan mengenai pelanggaran berat HAM dan kebebasan fundamental yang terjadi. Kedua
Kelompok Kerja tersebut akan bertemu setidaknya dua kali setahun selama lima hari setiap periode.

Prosedur menyediakan banyak pilihan mengenai langkah-langkah yang mungkin diambil Dewan sebagai kesimpulan dari proses tersebut.

\section{Special Procedure}

Merupakan suatu mekanisme yang ditetapkan Dewan HAM untuk mengatasi situasi spesifik suatu negara ataupun masalah-masalah tematis dunia. Saat ini terdapat 31 tematis dan 8 mandat negara untuk memperkokoh sistem review dan menjamin sinergi dengan mekanisme HAM yang lain dalam sistem PBB (http://ohchr.org/english/bodies/chr/sp ecial/index.htm).

Prosedur ini biasanya memanggil pemegang mandat untuk memeriksa, memantau, menasehati, dan secara terbuka melaporkan situasi HAM di suatu negara atau wilayah tertentu, dikenal dengan country mandates. Selain itu dikenal pula mandat tematik atau thematic mandates yang akan memeriksa pelanggaran-pelanggaran berat HAM diseluruh dunia. 
ISSN : 2356-4164

Berbagai kegiatandilakukan oleh Special Procedures, termasuk menanggapipengaduan

individu,melakukan studi, memberikan rekomendasi untukkerja sama teknisdi tingkat negara, dan terlibat dalam kegiatan promosi secara keseluruhan.

Prosedur khusus bagiindividu(disebut Special Rapporteur atau Pelapor Khusus,Special Representative of the Secretary-General atau Wakil Khusus Sekretaris Jenderal atauIndependent Expert atau Pakar Independen) atau kelompok kerjabiasanyaterdiri dari lima anggota(satu darimasing-masing wilayah regional).

Mandatprosedurkhususditetapkan danditentukan olehresolusi yang mereka keluarkan.

Pemegang

melakukankunjungan ke negaranegarauntuk menyelidikisituasi HAMdi tingkatnasional.Merekabiasanya mengirimkansuratkepada Pemerintah negara yang bersangkutanuntuk melakukan kunjungan jika pemerintah tersebutsetujuundanganuntuk mengunjungidiperpanjang. Beberapa negarapada prinsipnyasiap untuk menerimakunjungan

darisetiap pemegangmandat. Setelahkunjungan, pemegang mandat akan melaporkan segala permasalahan yang mereka temukandan rekomendasi-rekomendasi sesuai misi yang dilakukan.

Khususnya dalam masalah pelanggaran HAM terhadap individu yang terjadi pada tokoh demokrasi Myanmar Aung San Suu Kyi bahwasanya Dewan HAM PBB melalui United Nations High Commissioner for Human Rights(UNHCHR), Progress Report Special Rapporteur menegaskan untuk pembebasan segera Suu Kyi dari penahanan rumahnya. Menurut salah satu Resolusi Dewan HAM PBB A/HRC/13.48 par.39 menyebutkan The Special Rapporteur repeats his call for the termination of the detention of Daw Aung San Suu Kyi under house arrest, which is in contravention to international and domestic law.penahanan atas Suu Kyi bertentangan dengan hukum internasional dan juga hukum domestik.

Suatu negara sudah sepatutnya harus bertanggung jawab secara internasional menakala terjadi pelanggaran hak asasi manusia. Apabila tidak bertanggung jawab jelas bahwa 
ISSN : 2356-4164

negara yang bersangkutan akan mendapat sanksi internasional seperti embargo hingga dikucilkan dalam pergaulan internasional yang oleh Wolfgang Friedmann diistilahkan sebagai non participation sanction(Adji Samekto, 2009). Tidak hanya doktrin pertanggung jawaban negara yang dipergunakan dalam perlindungan hak asasi manusia, adanya doktrin mengenai intervensi juga menjadi bagian yang cukup penting digunakan dalam hukum internasional (Huala Adolf, 2002).

Kata intervensi terdapat dalam dokumen internasional Piagam PBB pasal 2 (7) dan 2 (4) yang mensyaratkan bahwa PBB dilarang ikut campur dalam urusan domestik suatu negara, “...to intervere in matters which are essentially within the domestic jurisdiction of any state", kecuali dalam rangka memelihara perdamaian menurut bab VII Piagam. Terdapat dua pandangan berbeda terhadap makna intervensi pasal 2 (7) Piagam PBB, pertama bahwa intervensi harus diinterpretasikan dalam arti teknis hukum internasional yang berarti adanya penggerogotan (usurpation) kedaulatan atau "intervensi diktator".Pendapat kedua menyatakan bahwa kata intervensi hanyalah pengertian kamus saja, hanya Dewan Keamanan sajalah yang mempunyai kemampuan untuk bertindak agar dapat mengakibatkan akibat hukum maka hal tersebut tidak merupakan "campur tangan/intervensi diktator".

Hukum Internasional memberikan pengecualian terhadap prinsip intervensi yang mana bahwa dalam keadaan tertentu tidak selalu merupakan sebuah pelanggaran atas integritas wilayah negara lain, yaitu :

a. Suatu negara pelindung telah diberikan hak-hak intervensi yang dituangkan dalam perjanjian oleh negara yang meminta perlindungan. Hal tersebut terjadi pada Perjanjian Persahabatan, Hubungan Bertetangga Baik dan Kerjasama antara Uni Soviet dan Afghanistan tahun 1978 di mana pasal 4 perjanjian tersebut menetapkan bahwa, akan mengambil langkah yang diperlukan untuk melindungi keamanan, kemerdekaan dan keutuhan wilayah kedua negara.

b. Jika suatu negara berdasarkan suatu perjanjian dilarang untuk mengintervensi, namun ternyata 
ISSN : 2356-4164

melanggar larangan ini maka negara lainnya juga adalah pihak dalam perjanjian tersebut berhak untuk melakukan intervensi.

c. Jika suatu negara melanggar dengan serius ketentuanketentuan hukum kebiasaan yang telah diterima umum, maka negara lainnya mempunyai hak untuk mengintervensi negara tersebut sebagai alasan pembelaan diri.

d. Jika warga negaranya diperlakukan semena-mena di luar negeri, maka negara itu memiliki hak untuk mengintervensi atas nama warga negara tersebut, setelah semua cara damai diambil.

e. Suatu intervensi dapat pula dianggap sah dalam hal tindakan bersama oleh suatu organisasi yang dilakukan kesepakatan bersama negara-negara anggota.

f. Suatu intervensi dapat juga sah manakala tindakan tersbut dilakukan atas permintaan yang sungguh-sungguh dan tegas-tegas dari pemerintah yang sah suatu negara.

Point (e) di atas, yaitu intervensi atas kesepakatan bersama negara-negara anggota suatu organisasi yang digunakan alasan dalam hal ini sebagai justifikasi terhadap tindakan yang diambil Dewan HAM PBB ketika menghadapi pelanggaran HAM di Myanmar.

Pelanggaran HAM yang dilakukan oleh Myanmar pun bukanlah pelanggaran HAM biasa melainkan pelanggaran berat HAM karena telah melakukan penahanan terhadap tokoh demokrasi Aung San Suu Kyi. Atas penangkapan dan penahanan secara sewenang-wenang terhadap Suu Kyi maka masyarakat internasional ikut melakukan kecaman terhadap Myanmar baik melalui organisasi internasional atau pun tindakan lain untuk ikut mengupayakan kebebasan bagi Suu Kyi.

Dengan berbagai mekanisme serta prosedur-prosedur yang terdapat di Dewan HAM menandakan bahwa dewasa ini hak asasi manusia sudah menjadi isu global yang melanda seluruh dunia. Jika suatu negara melakukan pelanggaran HAM terlebih merupakan suatu pelanggaran berat HAM maka masyarakat internasional seketika dan spontan akan memberikan reaksinya. Hal tersebut mengisyaratkan bahwa negara-negara tidak lagi dapat berlindung di balik kedaulatan teritorialnya atas pelanggaran 
ISSN : 2356-4164

hak asasi manusia yang terjadi di wilayah.Masyarakat internasional yang ikut melakukan inervensi terhadap Myanmar semata-mata hanya untuk menghentikan pelanggaran-pelanggaran berat HAM yang terus menerus terjadi di negara tersebut.

\section{SIMPULAN}

Era baru Dewan HAM PBB saat ini telah memberikan kewenangan kepadanya untuk dapat melakukan tindakan yang tegas sekalipun terhadap setiap pelanggaran HAM di seluruh dunia.Kinerja Dewan HAM yang konkret terlihat dalam upaya pembebasan seorang tahanan rumah sekaligus tokoh demokrasi Myanmar Aung San Suu Kyi. Dalam resolusi Dewan HAM A/HRC/10/19 tahun 2009 par. 38 disebutkan bahwa, "The Special Rapporteur reiterates his call for the termination of Daw Aung San Suu Kyi's detention under house arrest, which is in contravention of articles 9, 10 and 19 of the Universal Declaration of Human Rights..."Ketiga pasal tersebut sama sama menyebutkan bahwa seseorang berhak atas kebebasan untuk mengemukakan pendapat, larangan atas penangkapan sewenang-wenang hingga memiliki hak atas pengadilan yang adil dalam pasal 10. Adanya resolusi yang dilakukan oleh kelompok kerja (Special Rapporteur) tersebut membuktikan salah satu langkah Dewan HAM dalam ikut berperan aktif dalam pembebasan tokoh demokrasi Myanmar, Aung San Suu Kyi.

Penangkapan, penahanan, hingga peradilan yang sewenang-wenang yang dialami oleh Suu Kyi merupakan suatu kejahatan kemanusiaan yang bertentangan dengan prinsip-prinsip dasar hukum internasional.Atas dasar tersebut pula masyarakat internasional dirasa berhak untuk melakukan intervensi terhadap kedaulatan Myanmar sebagai suatu negara.Melalui mekanisme Universal Periodic Review Dewan HAM memiliki hak untuk meminta laporan dari setiap negara atas kondisi HAM yang ada di wilayah teritorialnya. Maka dalam $U P R$ $10^{\text {th }}$ di Geneva, 24 Januari - 4 Februari 2011 par. 29 disebutkan "The SecretaryGeneral, the High Commissioner for Human Rights, the Security Council, the General Assembly, the Human Rights Council and the Special Rapporteur on the situation of human rights in Myanmar called for the immediate release of Daw Aung San Suu 
Kyi, and of all remaining political prisoners." Artinya organ-organ tersebut telah mengeluarkan seruan-seruan agar pemerintah Myanmar segera membebaskan Aung San Suu Kyi dari tahanan rumahnya. Hal tersebut membuktikan bahwa jika pelanggaran HAM terjadi di suatu negara terlebih merupakan suatu pelanggaran berat HAM maka masyarakat internasional seketika dan spontan akan memberikan reaksinya. Selain itu juga mengisyaratkan bahwa negara-negara tidak lagi dapat berlindung di balik kedaulatan teritorialnya atas pelanggaran hak asasi manusia yang terjadi di wilayah negaranya, termasuk Myanmar. 
ISSN : 2356-4164

\section{DAFTAR PUSTAKA}

\section{BUKU}

Ambarwati, dkk, 2009, Hukum Humaniter Internasional dalam Studi Hubungan Internasional, PT. RajaGrafindo Persada, Jakarta.

Adji Samekto, 2009, Negara dalam Dimensi Hukum Internasional, PT. Citra Aditya Bakti, Bandung.

Boer Mauna, 2005, Hukum Internasional; Pengertian Peranan dan Fungsi dalam Era Dinamika Global, PT. Alumni, Bandung.

C. de Rover, 2000, To Serve \& to Protect Acuan Universal Penegakan HAM, PT. RajaGrafindo Persada.

Huala Adolf, 2002, Aspek-Aspek Negara Dalam Hukum Internasional (Edisi Revisi), PT. RajaGrafindo Persada, Jakarta.

Knut D. Asplund, Suparman Marzuki, Eko Riyadi, 2008, Hukum Hak Asasi Manusia, PUSHAM UII, Yogyakarta.

Masyhur Effendi dan Taufani Sukmana Evandri, 2010,HAM Dalam Dimensi Dinamika Yuridis, Sosial, Politik, Ghalia Indonesia, Bogor.

Sri Setianingsih Suwardi, 2004, Pengantar Hukum Organisasi

Jurnal Komunikasi Hukum
Internasional, Universitas Indonesia (UIPress), Jakarta.

\section{INTERNET}

Rudi M.Rizki, "Pokok-Pokok Hukum Hak Asasi Manusia Internasional", diakses pada tanggal 19 Maret 2016, URL: www.elsam.or.id/pdf/kursusham/Pokok pokok HAM Intl.pdf

Richard B. Bilder, "Tinjauan Umum Hukum Hak Asasi Manusia”, diakses pada tanggal 19 Maret 2016, URL: http://www.elsam.or.id/pdf/kursusham/ Tinjauan Umum Hukum HAM.pdf

Tomy Gutomo, "Makna Kemenangan NLD bagi Suu Kyi”, diakses pada tanggal 19 Maret 2016, URL :http://library.uinsby.ac.id/index.php/ne ws-and-events/947-makna-kemenangannld-bagi-suu-kyi

Renne R.A Kawilarang dan Shinta Eka Puspasari, 2009, "PBB: Penahanan Suu Kyi Melanggar Hukum”, diakses pada 19 Maret 2016, URL: http://dunia.vivanews.com/news/read/4 3454pbb-

penahanan suu kyi melanggar hukum

Universal Periodic Review, diakses 1 Maret 2016, URL :http://www.ohchr.org/EN/HRBodies/U PR/Pages/UPRmain.aspx

Background information on the Advisory Committee, diakses 3 Maret 2016, URL : http://www.ohchr.org/EN/HRBodies/HR C/AdvisoryCommittee/Pages/HRCACInd ex.aspx

Universitas Pendidikan Ganesha| 53 
Special Procedures of The Human Rights Council, diakses 3 Maret 2016, URL: http://www2.ohchr.org/english/bodies/ chr/special/index.htm

\section{INSTRUMEN-INSTRUMEN} INTERNASIONAL

\section{HUKUM}

Piagam PBB

Deklarasi Universal Hak Asasi

Manusia (UDHR)

ICCPR

Resolusi Majelis Umum PBB

Resolusi Dewan HAM PBB 